\title{
Elecciones, poder y antipoder en la República Democrática del Congo (1960-2019): el voto de lo "invisibilizado"1
}

\section{Elections, power and anti-power in the Democratic Republic of the Congo (1960-2019): The vote of the "invisible"}

\author{
MARCO ANTONIO REYES LUGARDO \\ Universidad Autónoma de la Ciudad de México-Cuantepec, México
}

Resumen: Análisis del avance de la razón universal de carácter metonímico y su inherente y constante lógica de producción de binomios y dicotomías capaces de producir repetidamente fronteras de carácter abisal que definen las zonas de no existencia, lugares de aquello que es definido como verdadero o ininteligible. Estos límites de pensamiento abisal o fronteras del no ser han sobrevivido a los procesos independentistas de África en general, y en particular al proceso de liberación nacional de la República Democrática del Congo. La persistencia de estas líneas abisales implica que las utopías de emancipación han perdido su potencial de liberación o que incluso han terminado por

Recepción: 12 de febrero de 2020. / Aceptación: 12 de marzo de 2020.

${ }^{1}$ Estas páginas hubiesen sido imposibles sin el apoyo y la generosidad del señor Mwangu Moses Joseph y del personal de la Kampala Capital City Authority Library, en Uganda. Mi eterno agradecimiento. 
convertirse en la contracara del pensamiento abisal. ¿Hay, entonces, más allá de lo que este pensamiento abisal determina como existente o no existente, alguna posibilidad de identificar fórmulas de antipoder cuyos términos de emancipación, subjetivación o instrumentalización escapen a la lógica del pensamiento abisal?

Palabras clave: emancipación; antipoder; matriz de poder colonial; instrumentalización del sujeto; colonialidad global.

Abstract: This article analyzes the advance of metonymic universal reason and its inherent logic of production of binomials and dichotomies that can constantly produce abyssal boundaries that define zones of non-existence; places defined as true or unintelligible. These abyssal lines or borders of non-existence have survived the independence processes in Africa, and particularly in the Democratic Republic of the Congo's national liberation. The persistence of these borders imply that the emancipation utopias have lost their potential for liberation, becoming the flipside of abyssal thinking. Beyond this abyssal thinking's definition of what does or does not exist, is it possible to identify anti-power formulas whose terms of emancipation, subjectivation or instrumentalization can overcome abyssal thinking?

Keywords: emancipation; anti-power; colonial power matrix; instrumentalization of the subject; global coloniality.

\section{Introducción}

Las últimas elecciones presidenciales en la República Democrática del Congo estaban oficialmente programadas para llevarse a cabo el 17 de noviembre de 2016. La negativa del expresidente Joseph Kabila -quien llegó a la Presidencia congolesa en 2001 como consecuencia del asesinato de su padre Laurent Kabila - a abandonar el cargo al final de su segundo y último mandato constitucional reactivó el uso de un antiguo término de hace más de medio siglo que aludía a las "patologías" de los presidentes africanos. "Crisis del Congo" fue una expresión 
que se empleó en enero de 1961, días antes del asesinato de Patrice Emmery Lumumba, y se refería a "desviaciones" respecto de un comportamiento considerado "normal". ${ }^{2} \mathrm{La}$ denominada "crisis del Congo" forma parte de la construcción de una geocultura biológica, evolucionista, lineal, que hace posible no sólo definir los "obstáculos que deben ser removidos tan pronto como sea posible” (Wallerstein, 1993, p. 213), sino también garantizar las condiciones de legitimación de intervenciones remediales.

A finales de la década de 1990, Immanuel Wallerstein (1996) advertía no sólo de los cambios hegemónicos en el sistemamundo capitalista moderno, sino también acerca de la antigüedad y la persistencia de una geocultura cuyo funcionamiento requería la producción y el consumo de imágenes de carácter negativo sobre el continente africano, el modo habitual en que los europeos han descrito a África durante cinco siglos por lo menos. Nos encontramos, entonces, en una época en la que somos testigos del reutilizamiento de viejos términos de características geoculturales. Esto obliga a pensar que, a lo largo del periodo colonial y de las décadas posteriores a los procesos de independencias africanas, se han preservado las descripciones o las representaciones negativas sobre el continente africano, sin importar los cambios en los liderazgos o las diversas hegemonías por las cuales ha transitado el sistema-mundo moderno y capitalista. La continuidad de esta geocultura permite también considerar que los modelos o utopías emancipadoras que han inspirado los movimientos sociales en el continente africano, desde sus procesos de independencia, han dejado intacta la estructura o matriz de poder colonial, lo que ha permitido que viejas representaciones sean recicladas o reutilizadas seis décadas más tarde.

${ }^{2}$ El documento emitido por la Special National Intelligence Estimate (1961), denominado "Main elements in the Congo situation", señala numerosos elementos por corregir para aliviar la "crisis"; a saber: "No hay gobierno central efectivo en el Congo", "la anarquía florece en la superficie", "la continua crisis política no puede evitar tener efectos serios en los sectores modernos de la economía”. 
Estas páginas intentan demostrar que, a lo largo de los últimos 50 años, la razón universal-metonímica ${ }^{3}$ ha sido capaz de imponer tanto los términos de subjetivación de las diversas emancipaciones como sus respectivos horizontes de llegada. La permanencia de esta geocultura hegemónica y de sus respectivas representaciones para el caso del continente africano obliga a pensar que las ciencias sociales han planteado interrogantes poco profundas a "problemas fuertes" que tácitamente han terminado por admitir la presencia de un "colonialismo sin fin" o incluso de un "capitalismo sin final" (Santos, 2014), términos muy convenientes para una "razón perezosa" que no va más allá de los límites establecidos por la propia regulación social y política. Dicho de otro modo, los análisis que hemos realizado sobre África, y en especial respecto a la República Democrática del Congo, han planteado sólo "preguntas débiles" a problemas fuertes, asumiendo que los paradigmas hegemónicos pueden resolver la enorme variedad o complejidad de las interrogantes. Por el contrario, para hallar las respuestas a "preguntas fuertes" tendrían que interrogar el paradigma societal y epistemológico que ha dado forma a nuestro horizonte de posibilidades, y por medio del cual decidimos cuáles opciones son posibles y cuáles son inimaginables (Santos, 2014, p. 43).

${ }^{3}$ Para Boaventura de Sousa Santos (2002, p. 239), la "razón metonímica” es una versión de la razón indolente que se reivindica a sí misma como la única forma de racionalidad y que, por lo mismo, no muestra interés en reconocer las partes o, en último caso, las usa como meras materias primas. Para la razón metonímica no pueden existir las partes fuera de su relación con la totalidad. Es, por tanto, inadmisible que alguna de las partes tenga vida propia más allá de la que le ha sido conferida. La razón indolente, en su variante metonímica, es capaz de convertir sus respectivos intereses en conocimientos verdaderos. Al ocultar su lugar de enunciación, la razón indolente esconde sus respectivos intereses y los presenta como conocimientos objetivos, libres de valores y válidos universalmente. Para la razón indolente resulta imposible separar la verdad de sus intereses, pues su objetivo fundamental es producir y reproducir las condiciones de existencia o inexistencia, fabulaciones, yacimientos terminológicos para el funcionamiento de una verdad universal, excluyente y única, donde el todo habla por las partes, incluso a través de las mismas partes. Estas últimas existen si y sólo si aceptan los términos de enunciación sobre los cuales se erige el todo. 
Esta sociología de las ausencias (Santos, 2002) o de todo aquello visible que ha sido invisibilizado, que existe porque no existe, de lo que ha sido reprimido, requiere invertir los términos epistémicos y de subjetivación (assujettissement), pues es un primer paso para voltear el mundo de cabeza, invertir la polaridad a fin de abrir un nuevo horizonte de visibilidad que haga posible advertir no sólo las luchas de quienes están reprimidos, sino también la pelea de lo que se encuentra reprimido (Holloway, Matamoros y Tischler, 2009, p. 19).

En suma, las siguientes interrogantes acompañan el análisis del presente trabajo: las crisis y constantes deposiciones de líderes africanos, que inicialmente son la solución y que posteriormente se transforman en "patologías", cobedecen a una relación entre epistemología y política en que la primera es usada por la segunda para justificar intervenciones salvacionistas (obtengo el poder y ergo libero)?, ¿es posible hallar "genes" de antipoder en algunos levantamientos populares recientes desplegados en la República Democrática del Congo que permitan observar acciones de lo que ha quedado subsumido, invisibilizado, por la lógica emancipadora propia de la razón metonímica que mandata que para liberarse del todo hay que convertirse en instrumento de ese mismo todo? En años recientes, ¿se han producido casos que puedan entenderse como ejemplo de antipoder (Holloway et al., 2009), donde la lucha por la emancipación no recurra a la instrumentalización de la lucha y que, por lo tanto, su objetivo no sea tomar el poder estatal?

\section{La primera "crisis del Congo"; la invención de África como región problema}

Hasta el día de hoy, la razón universal ha requerido para su expansión progresiva la creación de su propia antítesis, su andamiaje binario: zonas periféricas que fueron etiquetadas en un ejercicio de definición que ocultó su inherente violencia epistémica por haber sido construidas desde la bybris de punto 
cero, un lugar de enunciación desde el cual se construye la figura del observador desapegado que busca desinteresadamente verdades de manera objetiva y que "al mismo tiempo controla las reglas disciplinarias y se sitúa (él o ella) en una posición privilegiada para evaluar y definir” (Mignolo, 2010, p. 14).

Estas estrategias simbólicas de regiones de no existencia se convirtieron paulatinamente en importantes procesos de construcción y estructuración de las relaciones entre centro y periferia del sistema-mundo europeo capitalista: África fue inventada o reinventada como una región "problema", ubicada en una "etapa atrasada de desarrollo", a la cual había que tutelar para que fuese capaz de engancharse en la senda adecuada, lineal, conveniente de la historia. ${ }^{4}$ Esta patologización de la condición africana no sólo borró la responsabilidad europea en los procesos de marginación y explotación de los espacios colonizados, sino que justificó cualquier intervención tutelar que fuera capaz de aliviar esa desviación respecto al comportamiento "normal" de las sociedades europeas. ${ }^{5}$

La creación de regiones "patológicas" en la periferia en oposición a los llamados patrones de desarrollo "normal" de "Occidente" justificó una

${ }^{4}$ Para Santos (2002, p. 247), hay varias lógicas de producción de no existencia: i) aquella que se deriva de la monocultura del saber y del rigor disciplinario del saber y que consiste en transformar la ciencia moderna y de "alta cultura" en criterios únicos de verdad y calidad estética. Todo lo que no es legitimado por el canon dominante es declarado, en consecuencia, inexistente. "La no existencia asume aquí la forma de ignorancia o de incultura" (p. 247), y ii) la inherente a la monocultura del tiempo lineal que implica que la historia tiene o debe tener un sentido y dirección de carácter único y conocido. "Este sentido y esa dirección han sido formulados de diversas formas en los últimos 200 años: progreso, revolución, modernización, desenvolvimiento, crecimiento, globalización. El común denominador de todas estas formulaciones radica en la idea de que el tiempo es lineal, y que al frente de dicho tiempo se hallan los países centrales del sistema mundial y, con ellos, los conocimientos, las instituciones y las formas de sociabilidad que en ellos dominan” (p. 247). Esta forma de producción de no existencia produce la no contemporaneidad de lo contemporáneo.

${ }^{5}$ El Acta británica de la década de 1940 en África y sus apelaciones al desarrollo fueron, ciertamente, como afirma Cooper (1991, citado por Escobar, 2014, p. 75), una estrategia para reconstruir el mundo colonial y reestructurar las relaciones entre colonias y metrópolis, un esfuerzo por revitalizar la influencia y el poderío imperial en África. 
intervención política y económica por parte de los poderes imperiales. Al tratar al "Otro" como "subdesarrollado" y "atrasado", se justificaba la dominación metropolitana en nombre de la "misión civilizadora" (Grosfoguel, 2006, p. 37).

Hasta antes del final de la Segunda Guerra Mundial, tanto la URSS como Estados Unidos coincidían en que cualquier descolonización precipitada resultaría peligrosa. Estas concordancias, y la cautela de Estados Unidos para no entrometerse en lo que consideraba una región de influencia europea, cambiaron, no obstante, con el final de la guerra. A partir de entonces, Estados Unidos ya no permitiría que las viejas potencias europeas decidieran los aspectos más importantes del continente; la vieja retórica de la modernidad entendida como salvación y novedad se complementó con la idea de progreso, autodeterminación nacional y democracia.

La retórica de la novedad se complementó con la idea de progreso. Salvación, novedad y progreso tomaron un nuevo rumbo $-\mathrm{y}$ adoptaron un nuevo vocabulario- después de la Segunda Guerra Mundial, cuando Estados Unidos arrebató el liderazgo a Inglaterra y Francia, y dio apoyo a la lucha por la descolonización en África y Asia e inició un proyecto económico global bajo el nombre de "desarrollo y modernización" (Mignolo, 2003, p. 41).

Por consiguiente, durante los primeros años de la década de 1950 no había grandes razones para pensar que el Congo Belga pudiera desviarse hacia otra senda que no fuera aquella capaz de continuar poniendo en marcha los componentes fundamentales para una economía moderna e industrializada fundada en la ciencia moderna y en una monocultura del saber. "Los reportes anuales alardeaban del rápido crecimiento económico. Durante la primera mitad del Plan Decenal (1951-1956), por ejemplo, la producción industrial se había triplicado [...] en 1958 la producción industrial alcanzó 8\% del PND de la colonia” (Reno, 2006, p. 46).

Pese a los alardes en materia económica que hacía el colonialismo belga en el Congo, el éxito de Kwame Nkrumah en 
la lucha por convertir Ghana en el primer país independiente de África marcó la pauta para muchas de las posteriores luchas independentistas del continente (Barr, 2011, p. 88). Lo que hasta entonces seguía siendo el Congo Belga no fue, en ningún caso, la excepción, y siguiendo el ejemplo ghanés, Patrice Emmery Lumumba, que desde tiempo atrás había dado ya importantes indicios de un marcado nacionalismo, fundó en 1958 el Movimiento Nacional Congolés, único partido de base nacional en esos años:

Lumumba fue un desvergonzado nacionalista, y después de asistir a la Conferencia de Estados Africanos Independientes de 1958 (un foro que incluyó a Franz Fanon y a Kwame Nkrumah de Ghana), Lumumba adquirió mayor compromiso en la persecución del panafricanismo como una ruta hacia la descolonización e independencia (Barr, 2011, p. 88).

Otros partidos políticos congoleses tenían una base de apoyo de menor alcance; tal fue el caso de la Alianza de los Bakongo (Abako), la organización liderada por Joseph Kasavubu y que integraba a la mayor parte de los opositores al proyecto de Lumumba. Pese a los éxitos económicos resaltados por la administración colonial belga, 1960 marcó un significativo punto de inflexión, ya que el ímpetu revolucionario y nacionalista había terminado por llegar al entonces Congo Belga, el núcleo duro de los intereses económicos y políticos de la descolonización. El 30 de junio de 1960, Lumumba lanzó un emblemático discurso en la ceremonia protocolar de la independencia congolesa:

No hemos olvidado que en las ciudades las mansiones eran para los blancos y las chozas en ruinas para los negros; que un negro no era admitido en los cines, restaurantes y tiendas reservadas para los "europeos"; que un negro viajaba en el compartimento, bajo los pies de los blancos en sus cabinas de lujo (Lumumba, 1960).

Días después de la declaración de independencia se produjeron levantamientos provocados por el anuncio de la africaniza- 
ción de los cuadros militares y por la diametral oposición ante dicha medida por parte de los militares belgas. La provincia de Katanga se declaró en secesión. Se produjo entonces lo que las potencias coloniales llamaron "crisis del Congo" (Wallerstein, 1996, p. 54). En menos de dos semanas después de la independencia, Bélgica ocupaba un lugar central en dos de los conflictos más visibles al favorecer y respaldar la separación de Katanga y la no africanización del ejército congolés.

Las declaraciones escritas y orales de Lumumba dejaban ver su perfil nacionalista ${ }^{6}$ antes que socialista, pero que Jrushchov apoyara algunas independencias como contrapeso a la hegemonía de los intereses capitalistas en África central permitió la comparación de Fidel Castro con Patrice Lumumba. ${ }^{7}$

Mientras trataba de defender los intereses nacionales (mantener a la rica provincia de Katanga dentro de la unidad nacional), Lumumba fue colocado en contra de los intereses económicos occidentales, los cuales estaban interesados en los minerales congoleses antes que en la unidad congolesa. Por lo mismo, lo que algunos denominaron una postura intransigente de Lumumba hacia la explotación neocolonial, otros lo percibieron como una postura antioccidental y anticapitalista. Esta última caracterización de Lumumba permaneció como la dominante entre muchas de las narrativas acerca de la República Democrática del Congo, puesto que convenientemente reforzaba las narrativas dominantes de la Guerra Fría (Barr, 2011, p. 90).

6 "Ni somos comunistas ni católicos ni socialistas. Somos africanos nacionalistas. Nos reservamos el derecho de escoger a nuestros amigos en concordancia con el principio de la neutralidad positiva". Véase Patrice Lumumba. The truth about a monstrous crime of the colonialists, 1961, pp. 105-115.

${ }^{7}$ El ultraconservador columnista y antiguo editor de Newsweek (nacido en Bélgica), Arnaud de Borchgrave, inadvertidamente documenta el importante papel desempeñado por quien fungía como segundo secretario de la embajada de Estados Unidos en Leopoldville en 1960, Frank Carlucci, durante la crisis del Congo de 1960, al desatar diversos y escurridizos rumores que circulaban alrededor de sí mismo y que aludían a que el temor de Washington acerca de un Castro africano no carecía de fundamento. Pero también afirmaba que Lumumba estaba listo para entregar su país a un sombrío capitalista de apellido Dettwiller (Bustin, 2002, p. 554). 
Si la conversión de los "salvajes" y "paganos" que se realizó en el siglo XVI se llevó a cabo mediante una retórica de la modernidad que hablaba de salvar al otro de sus propios barbarismos, la "crisis del Congo" fue construida con un lenguaje biológico y salvacionista que permitía aliviar desinteresadamente "una enfermedad que designa la alternativa entre la vida o la muerte", o bien "una puesta en suspenso de la continuidad" (Swampa, 2016, p. 140). La "crisis” representa una ruptura entre lo que acontece en el tiempo presente respecto a los patrones precedentes y que dificultan la continuidad hacia el futuro. Una patología en la senda lineal de los vectores de progreso (Koselleck, 2010).

Más allá de las disputas geopolíticas de la época, el término crisis evidenciaba un tratamiento que justificaba una retórica intervencionista y salvacionista promovida por una geopolítica del conocimiento en la cual se evalúa al "enfermo" en función de la necesidad de continuidad y linealidad del tiempo histórico requerido para el avance de la modernidad y de la razón universal en su faceta metonímica, para la cual nada existe fuera de la contemporaneidad impuesta por un tiempo de esencia lineal.

Si hay diversas formas de liquidar a una persona más allá de terminar con su vida, Lumumba no sólo fue asesinado, también fue “patologizado", convertido en "agente patógeno”, en experiencia inútil para una geocultura de la modernidad capitalista que requiere constantemente, para su ulterior funcionamiento, la producción y la reproducción de imágenes negativas sobre el continente. Lumumba fue transformado en la posibilidad de una desviación dentro de la necesaria linealidad del progreso histórico sin la cual la razón de carácter metonímico de la razón universal no logra avanzar.

Además de la "patologización” de Lumumba, la denomina$\mathrm{da}$ "crisis del Congo" se presentó como una lucha opuesta entre dos proyectos antagónicos, el liberalismo wilsoniano versus el marxismo-leninismo, cuando en realidad se trató de dos planes que habían terminado por ser iguales, esencialmente dos caras 
de una misma modernidad que prometía alcanzar la luz al final del túnel: el ofrecimiento de desarrollo, el compromiso teórico con los valores científicos, eurocentrados y de pretensiones universales, siempre mezclados con una idea de progreso y desarrollo infinitos 8 (Wallerstein, 1996, p. 65).

$\mathrm{La}$ "crisis congolesa" impidió cualquier posible pregunta respecto al lugar de enunciación tanto del marxismo-leninismo como del liberalismo wilsoniano al hacerlas ver como opciones antagónicas. Por lo mismo, la matriz de poder colonial permaneció intacta en los debates y las luchas de la época, independientemente del perfil de las facciones, ya fuesen socialistas o capitalistas. Los dos proyectos contribuyeron a la expansión de la colonialidad global en la medida en que ambos se apoyaron en las ideologías de identidad nacional, desarrollo nacional y soberanía (Grosfoguel, 2006, pp. 28-29).

El énfasis histórico que explica la Guerra Fría como el enfrentamiento entre dos modelos cuyos horizontes de emancipación eran supuestamente contrarios permitió preservar el ca-

${ }^{8}$ En clara oposición a varios autores que han construido una historiografía basada en lo que se denomina "un breve siglo xx", que abarca desde la Revolución rusa de 1917 hasta el desplome del Muro de Berlín y de la antigua URSS en otro modelo de base capitalista, Wallerstein sostiene la vigencia de un "largo siglo xx", el cual se inició en 1870 y cuyo término estaría por llegar hacia el 2050. Las diferencias entre un siglo Xx de larga duración y otro de corta vigencia no sólo son de carácter cuantitativo, sino que se desprenden de preguntarse cuáles han sido los procesos fundamentales a lo largo de dichas cronologías. Mientras que los defensores de un breve siglo xx consideran como su elemento emblemático y mayormente definitorio el ascenso y la caída del "socialismo realmente existente", autores como Wallerstein conciben como elemento definitorio el ascenso, el despliegue y la decadencia de la hegemonía estadounidense, que comenzó en 1870 y ahora estaría viendo su etapa concluyente. La fase de decadencia de Estados Unidos se inaugura con la revolución cultural de 1968 y la crisis económica de 1972-1973, cuyos efectos permanecen hasta la actualidad (Aguirre, 2005, p. 241). "De este modo, y reexplicando todo el siglo xx desde esta hegemonía de Estados Unidos, Wallerstein no sólo va a relativizar profundamente el papel del socialismo realmente existente - hasta el punto de afirmar que todas esas sociedades llamadas 'socialistas' no lo han sido, y no podían serlo, pues al ser partes del sistema-mundo como un todo, les era imposible escapar a su lógica esencial, a la que estaban fatalmente condenadas a volver, más tarde o más temprano y por una vía o por otra-, sino que también va a caracterizar a la primera y a la segunda guerra mundiales como una sola larga guerra moderna de treinta años" (Aguirre, 2005, pp. 241-242). 
rácter ventrílocuo de las independencias africanas. Ciertamente, al estar anclado a caballo entre las fronteras de la geopolítica mundial y las de la colonialidad, Patrice Lumumba desenmascaró el trasfondo racial del régimen colonial (la desigualdad de la ley ante la cual el blanco y el negro nunca fueron iguales, "indulgente para unos y cruel e inhumana para los otros"), pero abrazó las banderas de la "unidad nacional y popular" y el carácter soberano del Congo independiente (Lumumba, 1960). Lumumba piensa desde las fronteras que delinean las áreas de existencia y no existencia, diluye de manera breve el pensamiento binario y dicotómico propio del pensamiento abisal, piensa de manera muy breve fuera de las articulaciones y las relaciones de poder. Su asesinato hace imposible cualquier intento de revelación de otro tipo de relaciones alternativas que constantemente han sido ofuscadas por las dicotomías hegemónicas (Santos, 2002, p. 246).

Contradictoriamente, el proceso de subjetivación mediante el cual Lumumba logró convertirse en agente de su historia es también una importante herramienta de instrumentalización de la lucha. Las luchas anticoloniales en general, y en particular la independencia congolesa, paradójicamente adoptaron categorías de lucha, herramientas racionales de carácter universal (autodeterminación nacional, gobiernos del pueblo o democracia, desarrollo económico, conocimiento científico, el Estado como garante del progreso; véase Wallerstein, 1996, p. 52) que, en cuanto tales, terminaban por reafirmar la modernidad y la razón universal. Las luchas independentistas, en consecuencia, fueron víctimas de la "paradoja de la subjetivación" (assujettissement), es decir, fueron subordinadas o subalternadas por aquellos procesos que en paralelo las reconocían o convertían en sujetos conscientes de sí mismos y en agentes de cambios sociales.

Deslumbradas por el entusiasmo de los cambios, y el progreso y el brillo de la modernidad (Mignolo, 2004, p. 227), las banderas de lucha de los movimientos de emancipación, si bien fueron adoptadas por las élites negras africanas, también 
ignoraron la colonialidad del poder y del saber, la continuidad de formas coloniales de dominación que subsisten al final de la colonización (Grosfoguel, 2006, p. 28). En consecuencia, la descolonización africana desató la agencia social de los sujetos en busca de la emancipación, pero a la vez colocó las luchas entre las prácticas reiterativas, instrumentalizadoras o rearticuladoras, siempre inherentes al poder y nunca como una relación externa de oposición absoluta a éste (Buttler, 1993, p. 5, en Mahmood, 2019).

La figura de Lumumba recuerda que hay varias maneras no sólo de aniquilar históricamente, sino también de no existir, nunca unívocas, y que tampoco hay una manera única de producción de la no existencia; mediante éstas la razón metonímica produce la no existencia de lo que no cabe en su totalidad y en su tiempo de carácter lineal. "La producción de la no existencia se produce siempre que determinada entidad es descalificada y tornada invisible, ininteligible o descartada de una manera irreversible" (Santos, 2002, p. 247). Lumumba fue aniquilado al ser convertido en el elemento "patológico", imposible de entender en la relación del todo con las partes y cuya "intransigencia" lo llevó a generar el "caos", "un peligroso izquierdista buscador de problemas" (Hochschild, 1998, p. 3). Durante la "crisis congolesa", la razón indolente, en su versión metonímica, produjo de nuevo explicaciones binarias excluyentes, dicotomías esenciales para su funcionamiento: el veneno y el envenenado, el antídoto y el curandero, la producción del caos y la necesidad de orden.

\section{Mobutu Sese Seko: Avant moi le chaos, après moi, le déluge.} Las razones del "caos"

La conversión de Patrice Lumumba en una "patología" causante de la "crisis congolesa" permitió también que su asesinato fuera presentado como un hecho que requería una acción remedial, una intervención capaz de recolocar a la República Democrática 
del Congo dentro de un orden, habitus, ethos, telos modernocapitalista que se requería para reencauzar el país en esa senda rectilínea que desemboca en un futuro siempre considerado mejor, la sustitución del "caos" por el orden, la remoción de un elemento "patógeno" que compromete el orden "natural". Lumumba fue violentamente asesinado el 17 de enero de 1961. A decir de Kuklick (2014, p. 145), el gobierno de Estados Unidos otorgó su respaldo a Mobutu Sese Seko, quien terminó por gobernar durante más de 30 años la República Democrática del Congo (1965-1997).

Muy poco después de tomar el poder en noviembre de 1965, y de remover al presidente Joseph Kasavubu y al primer ministro Evariste Kimba, el teniente general Mobutu anunció a la prensa que sus acciones no habían sido un golpe militar, sino un deber llevado a cabo para salvar al país de la anarquía y el caos (Kabwit, 1979, p. 385).

La extrema violencia usada para eliminar a Lumumba se dispensó en la medida en que el régimen sustituto fue capaz de actuar como garante de las condiciones de producción y reproducción del orden requerido para la modernidad capitalista. Por lo mismo, en sus primeros años de gobierno, Mobutu fue claro al respetar la lógica productivista de la modernidad capitalista, en la que el crecimiento económico se convierte en objetivo racional y criterio incuestionable de productividad aplicados tanto a la naturaleza como al trabajo (Santos, 2002, p. 249).

Por lo anterior, los primeros discursos y acciones de Mobutu fueron muy bien recibidos por la población, que, en general, temía el estallido de una nueva guerra civil. Con la meta principal de consolidar su poder, Mobutu emprendió medidas administrativas tendentes a la construcción de un gobierno centralizado. ${ }^{9}$

${ }^{9}$ Estas medidas y la creciente autoridad en manos de Mobutu terminaron, paulatinamente, por desembocar en una enorme concentración de poder, fenómeno que autores como Claude Willame (1971, pp. 1-2) han denominado modelo "cesarista”. 
Mobutu creó un aparato administrativo centralizado manejado por tecnócratas universitarios entrenados y por un servicio de carácter civil que reducía el grado de independencia de los ministros. Otro significativo paso tomado por Mobutu fue la progresiva eliminación de las filas gubernamentales de los así denominados "gobernantes patrimoniales" (Kabwit, 1979, p. 385).

Otro ejemplo de las disposiciones puestas en marcha por Mobutu al inicio de su mandato fue expulsar al cuerpo diplomático de la URSS y Checoslovaquia. "Desde su llegada al poder en 1965, Mobutu ha tomado grandes decisiones para rehabilitar su país ante los ojos del mundo, y para traer estabilidad económica y política en casa. La ley y el orden regresaron al Congo en contraste con el caótico periodo de 1960-1965" (Kabwit, 1979, p. 387).

Autores como Young y Turner (1985) analizaron los primeros cinco años del gobierno de Mobutu y aseguran que la captación de impuestos se incrementó, la inflación se redujo y la economía llegó a crecer en 8\% (MacGaffey, 1987, p. 420). De similar modo, Kabwit (1979, p. 401) confirma el éxito mobutista, pues durante los cinco años posteriores a la toma del poder, su régimen resultó muy exitoso en implantar la ley y el orden posteriores al caos y la anarquía, dicotomías que garantizaban la existencia de las partes a partir del todo. Mobutu y sus aliados extranjeros lograron el desarrollo de una economía que había sido originalmente evaluada como "estancada".

De hecho, el cesarismo de Mobutu había mostrado en sus primeros días resultados muy positivos en términos de la economía nacional. Ordenó una drástica devaluación como parte de las reformas monetarias de 1967, y en 1968 lanzó un código de inversiones que terminó por atraer el capital extranjero proveniente de Estados Unidos, Japón, Alemania Occidental y otras naciones occidentales, a la par que se redujo la dependencia respecto a Bélgica. Como resultado de lo anterior, en 1969 el Banco Nacional reportó por vez primera que el producto nacional bruto había sobrepasado al de junio de 1959. El país tuvo también un superávit en la balanza de pagos, y las reservas de divisas alcanzaron los 250 millones de dólares, en gran medida como consecuencia del alto precio del cobre, la principal exportación del país (Kabwit, 1979, p. 401). 
Según Young y Turner (1985, p. 325), a pesar de los éxitos económicos del mobutismo en sus primeros cinco años, la agricultura fue abandonada, la coerción se incrementó y el precio del cobre se desplomó. Ante estas circunstancias, Mobutu realizó un viraje significativo con una profunda política de nacionalización de empresas y activos. Contrario a lo que Young y Turner describen como acciones muy sui generis de nacionalización económica en los primeros años de la década de 1970, Mobutu no hizo más que responder a las condiciones del mismo modo que los otros países lo estaban haciendo ante un escenario económico de alcances mundiales.

El periodo entre 1968 y 1989 evidenció el gradual desmoronamiento de lo que restaba del consenso liberal. Por la derecha, los conservadores buscaban con más fuerza cada vez la destrucción del centro liberal. "Compárese la afirmación de Richard Nixon -'hoy día todos somos keynesianos' - con la campaña de George Bush en 1988 en contra de la 'palabra L'; L representaba al liberalismo” (Wallerstein, 1994, p. 145).

Las dificultades por las cuales atravesó el Congo Belga (luego Zaire) durante la primera mitad de la década de 1970 tuvieron detonantes muy diversos; a saber: la drástica caída de los precios del cobre y de otras mercancías exportadas; el cierre del ferrocarril de Benguela como consecuencia de la guerra civil en Angola (1973-1975); el alza de los precios del petróleo; un mundo en profunda recesión y los efectos negativos de las políticas de la zairenización. En realidad, el periodo de 1968-1973 puede considerarse como una época de "crisis" económica mundial, en la que el "sistema-mundo capitalista ha entrado más bien en la 'etapa final' de su ciclo histórico de vida, es decir en una situación de bifurcación histórica" que involucra una "crisis terminal' y de todas sus estructuras" (Aguirre, 2005, p. 247). Sin asumir que la zairenización haya sido la panacea a los problemas de Zaire, para la matriz de poder colonial, que genera líneas abisales infranqueables sin las cuales el avance de la modernidad liberal no puede desarrollarse, la política de tradicionalización mobutista fue la posibilidad de movimiento más allá 
de los límites de la relación entre factores binarios, fue un instante de acción desde las márgenes abisales del sistema dicotómico.

\section{Mobutu: la zairenización que lleva al "colapso"}

A partir de la década de 1970, Mobutu lanzó un nuevo rumbo para alcanzar la "grandeza del país", la "identidad nacional" y el "reconocimiento internacional". En octubre de 1971, anunció que el nombre del país sería sustituido por el de Zaire como parte de una política de "autenticidad".

La autenticidad nos ha hecho descubrir nuestra personalidad mediante la búsqueda en las profundidades de nuestro pasado, en la rica herencia cultural que nos fue legada por nuestros ancestros. No tenemos intención de regresar de manera ciega a nuestras costumbres ancestrales; más bien deseamos escoger aquellas que se adapten bien a la vida moderna, aquellas que favorezcan el progreso, y aquellas que sean capaces de crear un estilo de vida y de pensamiento que sea esencialmente nuestro (Kabwit, 1979, p. 389).

La política de autenticidad emprendida por Mobutu generó fuertes y controvertidos debates. Para algunos se trataba de una doctrina de carácter irrelevante y muy mal acondicionada para funcionar en las estructuras del Estado nacional. Otros llegaron incluso a compararla con el concepto de négritude de Leopoldo Senghor. "Pese a todas las críticas, en lo que respecta a Mobutu y los cuadros del Movimiento Popular de la Revolución, ${ }^{10}$ la autenticidad es considerada como una poderosa ideología nacional que debería ser capaz de lanzar a Zaire en una nueva senda" (Kabwit, 1979, p. 389).

${ }^{10}$ El Movimiento Popular de la Revolución era el partido único, creado por el propio Mobutu como parte de una reforma constitucional en el año de 1967 y que tuvo como objetivo reemplazar el sistema bicameral anterior por otro de una sola cámara. Los partidos políticos fueron también abolidos para crear el Movimiento Popular de la Revolución. 
Después de su viaje a China y de un acercamiento a Mao en los primeros días de 1973 (Chairman Mao meets president Mobutu, 1973, p. 23), Mobutu implementó el Salongo o política de trabajo duro y confianza nacional basada en la política de masas que había atestiguado en China y Corea del Norte. Los organismos financieros internacionales retiraron su respaldo al régimen congolés ante las medidas anunciadas. Durante la segunda mitad de la década de 1970, la política de zairenización fue abandonada, Mobutu retornó a la zona de no ser en la cual, según las instituciones financieras internacionales, debía haber permanecido, y como evidencia de lo anterior, terminó por abrir nuevamente las puertas a los viejos dueños de plantaciones, compañías y comercios. Zaire se declaró en retraso de pagos en 1975 y el "enfermo" pidió la asistencia "médica" requerida. De tal modo, el Zaire mobutista fue reencauzado en la senda correcta del "orden liberal internacional" (Cejas, 2000, p. 87).

El abandono de la política de zairenización como política de Estado hizo posible que el Fondo Monetario Internacional (FMI) regresara al país y trajera consigo el primer acuerdo de estabilización, que implicaba un préstamo de 47 millones de dólares y la promesa, ante los temores de los bancos internacionales, de que para 1976 ciertas condiciones económicas se alcanzarían. El FMI ordenó una devaluación de $42 \%$, el cierre a las importaciones, reducciones al gasto presupuestario e incentivos al sector agrícola (Schoenholtz, 1987, p. 422).

Lo que en realidad ocurrió fue que el presupuesto general, calculado para 69 millones de dólares, terminó por dispararse a 360 millones; los retrasos en pagos de deuda, calculados para descender por debajo de los 70 millones, se incrementaron mucho más; por su parte, la inflación -que alcanzó a la mayoría de la población, ya de por sí empobreci$\mathrm{da}-$ resultó rampante. Pero, dado que las medidas desnacionalizadoras fueron anunciadas y la moneda fue devaluada, el FMI terminó por aprobar el crédito (Schoenholtz, 1987, p. 422). 
Pese a que los efectos de las medidas fueron por demás magros, Mobutu obtuvo su cuota de respaldo internacional para continuar. En 1978, el FMI promovió la presencia de un buen número de expertos en las posiciones clave de la economía congolesa. Erwin Blumenthal, importante banquero alemán ya retirado, fue colocado como pieza clave en el Banco Central de Zaire. La profundidad de la corrupción y el control de la élite gubernamental provocaron la retirada de Blumenthal en 1979. Estados Unidos, por su parte, hacía fuertes gestiones ante el Club de París para que la deuda congolesa fuera condonada (Reno, 1997, pp. 41-42).

La paciencia con Mobutu parecía no tener límite durante la Guerra Fría. Desde 1976 hasta 1990, los oficiales del FMI desplegaron 14 programas de estabilización para Zaire. Entre 1975 y 1985, un tratamiento por demás gentil en las negociaciones del Club de París condujo a la reducción de 3.5 billones de dólares de la deuda de 7.5 millones de millones que Zaire había acumulado hacia 1985 (Reno, 1997, p. 42).

En 1983, Zaire no pudo cumplir a tiempo con el servicio de pago de deuda y Mobutu declaró un año de extrema astringencia económica: hubo una nueva devaluación de $77.5 \%$ y con ello sobrevino un alza generalizada de productos básicos (Schoenholtz, 1987, p. 423). A pesar de que el FMI y otros planificadores de las instituciones occidentales consideran que hicieron un diagnóstico adecuado y que el desplome económico fue en realidad responsabilidad de los "trucos mágicos" de Mobutu y su élite, valdría la pena recordar que Mobutu llegó al poder con el apoyo occidental hacia mediados de la década de 1960, y con la guía de los intereses mineros europeos.

Los expertos del FMI y el Banco Mundial (BM) fueron quienes determinaron como mejor opción encerrar a Zaire en un modelo de crecimiento basado en las exportaciones (Schoenholtz, 1987, p. 424). Las severas condiciones económicas impuestas por ambas instituciones sólo pudieron ser instrumentadas por un gobierno fuertemente autoritario y vertical, por Estados muy centralizados (Cejas, 2000, pp. 85-86). Poco a poco, el Es- 
tado cuyo objetivo había sido promover el desarrollo y el orden liberal terminó por develar su esencia autoritaria al convertirse en un "Estado contradesarrollista" (Braeckman, 1992, pp. 213 y ss.). Se hizo necesaria una nueva intervención a fin de que el autómata volviera a ganar el juego (Benjamin, 2008). En ninguno de los casos hubo intención de colocar las bases para que los congoleses fueran agentes de sus propias historias. Este mismo "conocimiento ventrílocuo" (Guerrero, 2010, p. 21) nos condena a repetir lo extraño y nos aleja de la construcción de una historia que haga posibles otros actores, saberes, vivires, conocimientos, que desde el montaje de la razón colonial han estado invisibilizados, pero también en resistencia, en insurgencia material.

Más allá de los “trucos mágicos” atribuidos a Mobutu, habría que reconocer un número importante de factores que contribuyeron al declive de su gobierno. Los programas de ajuste estructural y las medidas de privatización del FMI y el BM contribuyeron también de modo importante al colapso del Estado zairense (Raeymaekers, 2008, p. 8). En sus últimos años de gobierno, como parte del paquete de condiciones impuestas por el FMI y el BM, Mobutu hubo de implementar normas de apertura democrática. Una de las más visibles fue la convocatoria y celebración de la Conferencia Nacional Soberana, la cual buscaba definir la estructura institucional que regiría a lo largo de un periodo de transición hacia lo que se comenzó a llamar "la Tercera República". "El colapso del bloque comunista introdujo nuevas dinámicas en la lucha zairense en contra del dictador Mobutu. La democracia se convirtió en uno de los temas predominantes en la mayor parte de los países con sistemas opresivos. Zaire no fue una excepción” (Mabiengwa, 1999, p. 680).

Una oleada de Conferencias Nacionales se inició en Benín el 19 de febrero de 1990. Ante la presencia de los representantes de las principales instituciones financieras internacionales, $\mathrm{Ma}$ tías Kérékou, presidente de Benín desde 1972, hizo un llamado a la renovación política y a la implementación de los programas de ajuste estructural del FMI (Robinson, 1994, p. 575). A diferen- 
cia de la experiencia de Benín, en que el presidente Kérékou recuperó incluso el cargo presidencial después de las reformas de ajuste, el régimen mobutista terminó en un "colapso estatal".

La toma del poder en Kinshasa el 17 de mayo de 1997 por parte de la Alianza de Fuerzas Democráticas para la Liberación de Congo (AFDL) marcó el colapso de Zaire, un Estado de 32 años de edad que había sido creado por Mobutu Sese Seko a partir del caos original del Congo, y que había sido sostenido con la ayuda en diferentes épocas de sus aliados occidentales, Bélgica, Estados Unidos y Francia (McNulty, 1999, p. 53).

El Estado, institución que había tenido un papel central en las discusiones relacionadas con los procesos de desarrollo en África, terminó por convertirse en una de las instituciones mayormente vilipendiadas, ya fuera por su debilidad o por su fortaleza, o bien por su ubicuidad o su ausencia. "Ahora se habla de 'estados rentistas', 'estados atrofiados', 'estados parasitarios', 'estados predatorios', 'estados prebendalistas', 'estados cómplices', 'estados cleptocráticos', 'estados invertidos' (Mkandawire, 2001, p. 293).

El punto extremo de este proceso de "degeneración" fue descargado sobre Zaire y Mobutu; el colapso estatal se presentó como un "malestar" provocado por el desarrollo que debía revertirse mediante una intervención capaz de combinar sanciones rápidas, asistencia externa y construcción de instituciones. El colapso estatal ocurrió en la mayor parte de los casos, asegura Raeymaekers (2008, p. 4), como condición final y crítica de una "enfermedad degenerativa". Esta definición implica que hay Estados "normales" y otros más que sufren una patología que los lleva a extremos "problemas de gobernanza". Zartman (1995) alude al colapso como un momento en el cual la estructura, la autoridad y el orden político se han desplomado y deben ser reconstituidos de una forma u otra.

El colapso estatal en tanto diagnóstico eludió cualquier posibilidad de interrogarse acerca de la naturaleza del Estado en África, su esencia patriarcal, eurocéntrica, u otras alternativas a la institución estatal. Si el término de la Guerra Fría 
permitió oscurecer el lugar de enunciación tanto del liberalismo wilsoniano como del marxismo-leninismo y sus respectivas coincidencias en materia de creencia en la modernidad y progreso como una "meta dorada" al final del túnel (Wallerstein, 1996), también permitió una reconstrucción del Estado sin hacer una crítica profunda al ethos, telos y habitus que, en tanto estructura esencialmente moderna, capitalista y eurocentrada, persigue. El "colapso" permitió relegitimar de manera acrítica el orden existente mediante la reconstrucción estatal (Wallerstein, 1994):

Una vez concluida la Guerra Fría, los Estados africanos fueron requeridos a seguir una serie de pautas que los llevaran a reducir sus respectivos tamaños, estabilizar la economía, engancharse en la "buena gobernanza", llevar a cabo un proceso de democratización de sí mismos y de sus respectivas sociedades, además de asegurar un "ambiente favorable" para el desarrollo del sector privado (Mkandawire, 2001, p. 289).

Hasta antes de la década de 1980, los economistas del вм у del FMI sostuvieron que el pobre desempeño económico de los países africanos se explicaba por las fallas en la implementación de las políticas de ajuste por parte de los gobiernos respectivos. Hasta ese momento, no había ningún señalamiento en torno al concepto de gobernanza (governance). El BM publicó, entonces, ejemplos exitosos de países que habían alcanzado grandes logros en materia de estabilización macroeconómica. El reporte fue un pesado argumento para aquellos que se habían opuesto o demorado en emprender las reformas señaladas por las instituciones financieras internacionales. Faltaba documentar los casos de los países que, aun cuando emprendieron las reformas, no obtuvieron los resultados anhelados. Para estos últimos, la respuesta fue "debilidad institucional" o mala gobernanza (bad governance).

Los nuevos proponentes de la buena gobernanza argumentaron que las políticas eran buenas per se, y que la buena gobernanza significaba también la implementación de la política económica ortodoxa. La buena gobernanza se convirtió, entonces, en otro instrumento más para la im- 
plementación de los programas de ajuste estructural. Dado que las políticas macroeconómicas eran sacrosantas, era importante que las instituciones democráticas que llegaran a surgir con la buena gobernanza no fueran usadas para socavar la política económica. Esto fue asegurado mediante la introducción de reformas institucionales que pudieran comprometer la autoridad de los cuerpos electos y a través del aislamiento de los tecnócratas, al igual que mediante la creación de autoridades autónomas (Mwandawire, 2007, p. 681).

Al igual que Lumumba, Mobutu terminó por convertirse en elemento prescindible, una experiencia inútil para una matriz de poder colonial que se afana en cambiar las sociedades catalogadas como atrasadas, pero que terminan en lo contrario de lo que se pretende alcanzar. Lo que empezó como una salvación, se convirtió en su opuesto. Los iniciados en esta dinámica de conquista del poder, tal como fue Mobutu, ni siquiera llegan a ver lo lejos que se han sumergido en la forma de razonar y ejercer los hábitos del poder (Holloway, 2005, p. 21). De haber sido presentado como el garante del "orden", el elemento necesario para extirpar el cuerpo "patógeno", Mobutu se convirtió en esto último. Cuando la discusión se centra en quién posee el poder, el debate queda limitado a quién debe ejercerlo y, en consecuencia, la manera de cambiar el poder es simplemente la conquista del Estado. Esta misma dinámica dicotómica, que se enfoca en la toma y el control del poder del Estado como medio para impulsar los cambios en la sociedad, es lo que subyace en las recurrentes "crisis congolesas".

\section{$M z e e^{11}$ Kabila, mtoto Kabila y el ascenso de lo "no existente"}

Laurent Kabila llegó a Kinshasa el 17 de mayo de 1997. Su acceso al poder estuvo marcado por una profunda expectativa

${ }^{11}$ Mzee y mtoto se han tomado del kiswahili como términos que, respectivamente, significan 'anciano' y 'niño'. Ambas palabras son usadas para referirse a Laurent Kabila y Joseph Kabila. 
de parte de los congoleses. Muchos recibieron a mzee Kabila como libertador de las duras condiciones económicas y políticas a las cuales Zaire había llegado en los últimos días (Ridao, 1997, p. 45). Pese a lo anterior, Kabila reveló rápidamente los compromisos iniciales que había adquirido para tomar el poder. No aplicar los Acuerdos de Lusaka que él mismo había firmado, se tradujo en la pérdida del respaldo con el que había iniciado su gobierno. El 16 de enero de 2001, Laurent Kabila fue asesinado por uno de sus guardaespaldas. Su hijo, Joseph Kabila, fue designado por el poder kabilista como nuevo jefe de Estado (Kabunda, 2001).

Mtoto Kabila heredó un territorio ocupado por las milicias que usufructuaban una economía de guerra. A diferencia de su padre, Joseph Kabila condicionó la puesta en marcha de los Acuerdos de Lusaka a la retirada de la tropas ruandesas y ugandesas involucradas en el saqueo de recursos minerales (Kabunda, 2001, p. 31). Cinco años después, Kabila participaba en las primeras elecciones en la historia congolesa después de más de cuatro décadas. Paulatinamente, un gobierno transicional se fue definiendo hasta que quedó integrado bajo la fórmula "1 + 4". ${ }^{12}$ En los primeros años del siglo xxI, para el World Bank (2004) la República Democrática del Congo era un caso de "debilidad institucional" que requería "respaldo a la gobernanza" y "fortalecimiento institucional". La integración de los antiguos señores de la guerra a la política partidista permitió su desmovilización, de modo que, después de un largo proceso de pacificación, las elecciones se celebraron el 30 de junio de 2006, comicios en los cuales, en una segunda vuelta electoral, la victoria correspondió a Joseph Kabila. La democratización se

${ }^{12}$ Una fórmula que integraba a un presidente (Joseph Kabila) acompañado de cuatro vicepresidentes. Entre estos últimos destacan los líderes de las principales facciones rebeldes que, desde el final del régimen de Mobutu, habían intervenido en territorio congolés para conformar una economía extractiva de recursos; a saber: Jean Pierre Bemba (Movimiento para la Liberación del Congo) y Azarias Ruberwa (Agrupación Congolesa para la Democracia), ahora convertidos en líderes de los principales partidos políticos, y a quienes les asignó cargos dentro de las estructuras del nuevo gobierno transicional. 
replicaba como espectáculo de expertos que decidían, en función de la fuerza armada o militar, quiénes habrían de convertirse en visibles o invisibles en la etapa de transición a la democracia. Cinco años más tarde, el presidente Kabila volvió a triunfar en los comicios de 2011. La mayor disputa para él vendría al final de su segundo mandato presidencial, ya que el texto constitucional congolés establecía con claridad que el 19 de diciembre de 2016 debía concluir su último periodo. Algunos representantes del gobierno de Estados Unidos habían ya previsto el escenario:

El secretario de Estado, John Kerry, ha advertido en repetidas ocasiones a la República Democrática del Congo. El gobierno de Estados Unidos es proclive a preservar sus intereses estratégicos y a evitar la alienación de muchos de los jóvenes africanos (327 millones de edades entre 15-24 años, casi una tercera parte de la población), quienes se muestran impacientes. En agosto de 2014, durante la primera cumbre entre Estados Unidos y África en Washington, Kerry sostuvo reuniones privadas con Kabila y con otros tres presidentes africanos en las que se enfatizó la necesidad de respetar los límites constitucionales en materia de los periodos presidenciales (Cessou, 2016).

Kabila hizo poco caso a las recomendaciones del gobierno de Estados Unidos y las elecciones no fueron convocadas con el argumento de que había falta de fondos y necesidad de realizar un nuevo censo poblacional. Una propuesta de modificación constitucional tendente a permitir un tercer mandato a Kabila había sido ya sometida al Congreso. La votación para modificar el texto constitucional debía llevarse a cabo el 19 de enero de 2015, pero varias manifestaciones realizadas en los primeros meses de ese año dejaron entrever que un tercer mandato kabilista no era una opción compartida por todos. Una población principalmente joven y encolerizada terminó por rebasar las demandas y las acciones de estudiantes y militantes de partidos antikabilistas. Los comercios chinos fueron saqueados, la "calle" hizo finalmente recapitular al poder kabilista en la búsqueda de la reelección presidencial (Polet, 2016, p. 135). De igual modo, 
varios partidos políticos conformaron una coalición, Dinámica de la Oposición, la cual hizo un llamado a la población a oponerse a los cambios en la ley electoral.

En este contexto, enero de 2015 fue testigo de la reactivación del concepto de "crisis congolesa", término utilizado por una vieja e incisiva geocultura que patologiza al continente africano, que lo convierte en un enfermo cuya salvación debe siempre provenir de la matriz de poder colonial. Human Rights Watch (s.f.) publicó varios documentos en los cuales identificaba una "crisis humanitaria". La Unión Europea comenzó a hacer alusión a una "crisis congolesa" que debía ser resuelta en los términos de la Constitución Política; advertía del "carácter urgente" de la situación, cuya solución radicaba en el respeto del límite de los mandatos presidenciales mediante las acciones de los actores autorizados, a saber: la Iglesia católica, los partidos registrados y la sociedad civil.

Si bien en otros casos africanos la prolongación o la permanencia de presidentes en el cargo no es catalogada como "crisis", en el caso particular de la República Democrática del Congo se recuperó el concepto justo cuando las movilizaciones de la "gente común" (Zibechi, 2011, p. 31) parecían desbordarse, deshacerse como ausencia y convertirse en presencia, manifestarse desde las entrañas del volcán. "Lo de afuera contiene, lo de adentro amenaza todo el tiempo con explotar, desbordar si el poder está afuera, lo que está adentro no es poder ni contra-poder, sino anti-poder, algo bien diferente" (Holloway et al., 2009, pp. 16-17). Se trata de un sujeto no instrumentalizado, "magma volcánico", que intenta salir de esa zona de no existencia adonde ha sido relegado por décadas de política partidista. La "crisis congolesa" de 2016 nos obliga a pensar ya no en términos de la dominación —como se hizo más arriba para explicar las "crisis" de los gobiernos de Patrice Lumumba y Mobutu Sese Seko-, puesto que ésta termina siempre por instrumentalizar las luchas de los sujetos emancipadores, sino desde la insubordinación, esto es, desde el "corazón reprimido pero rebelde de la sociedad”, desde aquellas manifestaciones de 
lucha extrainstitucionales que no se hacen por tomar el poder sino contra el poder (Holloway et al., 2009, p. 16).

Kabila hizo lo posible para bloquear las tentativas de acercamiento de parte de la oposición política respecto de la "calle", las movilizaciones de la gente común que no han sido convocadas por las organizaciones partidistas. La apropiación simbólica y física de la calle, que se ha convertido en un espacio primordial de la lucha política, que no puede ser entendido más que como una respuesta coordinada por el grito de "Yebela!" (palabra en lingala que significa "sáquenlo") y aquellas movilizaciones favorecidas por el jefe de Estado que entonan y bailan con el eslogan "Wumela!" ("Quédate por mucho tiempo") (Polet, 2016, p. 138).

El 8 de agosto de 2018, último día oficial para el registro de candidatos a la Presidencia, Joseph Kabila anunció que no se presentaría a un tercer mandato. El candidato oficial del partido entonces en el poder fue Emmanuel Ramazani Shadary, un personaje de toda la confianza del presidente Kabila. Las elecciones finalmente se celebraron el 10 de enero de 2019 y la Comisión Nacional Independiente anunció los resultados provisionales:

Contra todas las evidencias, Félix Tshisekedi, candidato de la coalición Cap pour le changement (Cach), ha sido proclamado vencedor con $38.57 \%$ de los votos; detrás de él se halla la otra coalición de oposición, Lamuka (Despierta), Martin Fayulu (34.83\%) y, finalmente, el delfín del presidente saliente Joseph Kabila, Emmanuel Ramazani Shadary $(23.84 \%)$, todos compitiendo en votación de una sola vuelta ${ }^{13}$ (Misser, 2019 , p. 8).

${ }^{13}$ En un análisis realizado por la Conferencia Episcopal Nacional de Obispos Congoleses, con una muestra electoral de 13.1 millones de electores, los resultados arrojados fueron muy diferentes: Fayulu (62.11\%); Félix Tshisekedi (16.93\%) y Ramazani (16.88\%). Para Misser (2019, p. 8), los datos oficiales fueron producto de una negociación entre Félix Tshisekedi y Kabila, quien, ante la derrota de su candidato, prefirió negociar con quien obtuvo los votos necesarios para alcanzar el segundo lugar. El arreglo le garantizó al partido oficial mantener una confortable mayoría de dos terceras partes en el Congreso. Félix Tshisekedi había ya dibujado ciertos acercamientos con el poder kabilista. Por el contrario, Fayulu, quien fue miembro de la ExxonMobil, 
El 20 de enero de 2019, la Corte Constitucional Congolesa terminó por proclamar la victoria definitiva de Félix Tshisekedi. Inmediatamente, Sudáfrica y los países africanos reconocieron al nuevo jefe de Estado congolés. La "calle", las protestas de la "gente común" quedaban nuevamente invisibilizadas por los órganos institucionales del poder. Diversos autores, concentrados en una epistemología de la dominación, atribuyen este eclipse de la "calle" y el "Yebela !" a la espontaneidad del movimiento y a la falta de liderazgo en la rebeldía. Se les trata como movimientos que "aún no" desarrollan suficiente conciencia.

Otras explicaciones conciben que se trata de movimientos que se rehúsan a ser cooptados, que rechazan servir de palanca para el Estado. Para Badiou (2012), representan nuevas formas de movimiento que escapan a la ontología moderna y eurocéntrica de lo que deben ser los sujetos sociales, y que, por ende, son capaces de cuestionar la esencia capitalista y defensora del statu quo del Estado, pues experimentan en sí mismos una enorme libertad de acción, siempre guiados por la utopía de "Otro mundo es posible" (Branch y Mampilly, 2015, p. 213).

\section{A modo de conclusión: las rebeliones de la gente común (el "Yebela !") inatrapable y el "Wumela !"}

A lo largo de este trabajo hemos visto la enorme capacidad de la razón metonímica para producir términos dicotómicos, excluyentes, binarios, que construyen permanentemente fronteras abisales, espacios del no ser que reproducen al infinito las imágenes y las representaciones propias de una geocultura moderna occidental que requiere de otro negativizado, oscu-

carecía de compromisos, pero Moïse Katumbi, antiguo gobernador de Katanga, al igual que Jean Pierre Bemba, le han dado un fuerte respaldo. 
recido, negado, ya que ello justifica la esencia intervencionista y expansionista de la razón metonímica sobre la cual se edifica la geocultura moderna occidental. Hemos privilegiado una episteme que subraya la dominación y no la insubordinación, cómo se toma el poder más que cómo se insubordinan los movimientos al poder.

No importa cuánto se defienda el movimiento y su importancia, el objetivo de obtener el poder involucra inevitablemente una instrumentalización de la lucha. La lucha tiene por objetivo conquistar el poder político. La lucha es un medio para alcanzar dicho objetivo. Aquellos elementos de lucha que no contribuyen a alcanzar el objetivo son considerados como secundarios o bien suprimidos en conjunto: se establece una jerarquía de las luchas. Esta instrumentalización/jerarquización es, al mismo tiempo, un empobrecimiento de la lucha (Holloway, 2005, p. 20).

Los análisis construidos sobre las “crisis congolesas” dejan intacta la discusión sobre la naturaleza del poder y se concentran principalmente en la pregunta de a quién debía pertenecerle. Tanto el lumumbismo como el mobutismo y las dos experiencias kabilistas - que iniciaron con un grito en contra del poder - terminaron convirtiéndose en su opuesto, en un agente reproductor de lo que al inicio criticaban, y adquirieron los hábitos, la ética y el telos del poder al cual decían combatir.

Las pasadas elecciones fueron parte de un fenómeno externo a las urnas. Ante el anuncio de Joseph Kabila de hacer los ajustes necesarios para asegurarse el poder y desde ahí promover cambios sociales, la multitud, el "Yebela!", salió a las calles. Esas protestas no estuvieron impulsadas por las viejas estructuras partidistas, ya muy desacreditadas en tanto instrumentos clásicos de la conquista del poder como justificación para promover cambios. Esa multitud que gritaba "Yebela !" desapareció después de que Joseph Kabila anunciara que no participaría para un tercer periodo presidencial. Para algunos autores, "las oleadas de protestas actuales han demostrado in- 
cluso menos alcances, ya que han fracasado profundamente en traer consigo cambios políticos profundos" (Branch y Mampi$11 y, 2015$, p. 5). Este tipo de explicaciones refleja que estamos tan acostumbrados a pensar los cambios, las emancipaciones o las revoluciones como sinónimo de "adueñarse del Estado", que cuando la "multitud", la "calle" o la "gente común" se repliega para desaparecer, pensamos que se trata de estallidos inconscientes e intrascendentes, que no aportan nada a una liberación o emancipación profunda.

Para Holloway (2005) ya no se puede construir una sociedad de relaciones de no poder por medio de la conquista del poder. La caída de la URSS hizo posible también la liberación del pensamiento revolucionario, de la unidad entre revolución y toma del poder del Estado. Las movilizaciones y las protestas de la segunda década del siglo xx en África se replegaron casi inmediatamente después de su entrada en acción porque estaban conformadas por aquellos sujetos sociales que siempre habían sido arrasados por un estilo hegemónico de hacer política que buscaba como objetivo último la toma del poder como justificación para promover cambios. Se trataba de movilizaciones que, por esa misma razón, no buscaban tomar el poder. Eran los que nunca habían estado porque siempre habían sido ocultados, negados, colocados en la zona del no ser, eran el antipoder que se halla por debajo de la superficie más visible (Holloway, 2005, p. 159).

Hay un mundo de luchas que a veces no dicen más que "¡No!", pero que muchas veces, en el proceso de decir ¡No!, desarrollan formas de autodeterminación o articulan conceptos alternativos de cómo debería ser el mundo. Estas luchas, si se reportan en los medios, están filtradas a través de los lentes del poder, visibles nada más en cuanto tienen un impacto en la política de poder (Holloway et al., 2009, p. 17).

El antipoder desea emanciparse del poder entendido como dominación, como represión del poder hacer. El antipoder no es una nueva forma de dominación, sino algo esencialmente 
diferente: una resubjetivación del sujeto emancipatorio que lo aleja de los procesos de conversión del sujeto en instrumento del poder.

\section{Referencias}

Aguirre, C. (2005). Immanuel Wallerstein y la perspectiva crítica del "análisis de los sistemas mundo". Revista Colombiana de Sociología, 25, 227-263. Recuperado de https://revistas.unal.edu.co/ index.php/recs/article/view/11377

Badiou, A. (2012). The rebirth of history: Times of riots and uprisings (Trad. G. Elliott). Londres: Verso.

BARR, B. (2011). Raoul Peck's Lumumba and Lumumba : La mort du prophète: On cultural amnesia and historical erasure. African Studies Review, 54(1), 85-116. https://doi.org/10.1353/ arw.2011.0006

Benjamin, W. (2008). Tesis sobre la historia y otros fragmentos (Trad. B. Echeverría). México: Universidad Autónoma de la Ciudad de México.

Braeckman, C. (1992). Le Dinosaure. Le Zaire de Mobutu. París: Fayard.

Branch, A. y Mampilly, Z. (2015). Africa uprising: Popular protest and political change. Londres: Zed Books.

Bustin, E. (2002). Remembrance of sins past: Unraveling the murder of Patrice Lumumba. Review of African Political Economy, 29(93/94), 537-560.

Cejas, M. (2000). Pensar el desarrollo como violencia: algunos casos en África. En S. B. C. Devalle (Comp.), Poder y cultura de la violencia (pp. 68-118). México: El Colegio de México. https:// doi.org/10.2307/j.ctv512rk7.6

Cessou, S. (2016). DRC's Kabila refuses to go. Le Monde diplomatique. Recuperado de https://mondediplo.com/2016/12/06 DRC

Chairman Mao meets president Mobutu (1973). Pekin Review, 37(3), 3-5.

Escobar, A. (2014). La invención del desarrollo. Bogotá: Universidad del Cauca. 
Grosfoguel, R. (2006). La descolonización de la economía política y los estudios postcoloniales: transmodernidad, pensamiento fronterizo y colonialidad global (Trad. M. L. Valencia). Tabula Rasa, 4, 17-48.

Guerrero, P. (2010). Corazonar. Una antropología comprometida con la vida. Miradas otras desde Abya-Yala para la decolonización del poder, del saber y del ser. Quito: Abya Yala-Universidad Politécnica Salesiana.

Hochschild, A. (1998). King Leopold's ghost: A story of greed, terror and heroism in colonial Africa. Nueva York, NY: Houghton Mifflin.

Holloway, J. (2005). Cambiar el mundo sin tomar el poder. Caracas: Melvin.

Holloway, J., Matamoros, F. y Tischler, S. (Comps.) (2009). Pensar a contrapelo: movimientos sociales y reflexión crítica. México: Bajo Tierra.

Human Righs Watch (s.f.). Democratic Republic of Congo in Crisis [blog]. Recuperado de https://www.hrw.org/blog-feed/democratic-republic-congo-crisis

Kabunda, M. (2001). El Congo después de Kabila: perspectivas de paz. Politica Exterior, 15(80), 29-37.

Kabwit, G. (1979). Zaire: The roots of the continuing crisis. The Journal of Modern African Studies, 17(3), 381-407.

Koselleck, R. (2010). historia/Historia (Trad. A. Gómez Ramos). Madrid: Trotta.

KukLICK, B. (2014). Killing Lumumba. Proceedings of the American Philosophical Society, 158(2), 144-152.

Lumumba, P. (1960). Discurso en la ceremonia de proclamación de la independencia del Congo (Trad. P. López). Recuperado de https:// www.marxists.org/espanol/lumumba/1960/junio/30.htm

Mabiengwa, E. (1999). The State of the State in Congo-Zaire: A survey of the Mobutu Regime. Journal of Black Studies, 29(5), 669-683.

MacGaffey, J. (1987). Patrimonial politics in Mobutu's Zaire. African Affairs, 86(344), 419-424. https://doi.org/10.1093/ oxfordjournals.afraf.a097923

Mahmood, S. (2019). Teoría feminista y el agente social dócil: algunas reflexiones sobre el renacimiento islámico en Egipto. Papeles del CEIC, 2019(1), 1-31. https://doi.org/10.1387/pceic.20282 
McNulty, M. (1999). The collapse of Zaïre: Implosion, revolution or external sabotage? The Journal of Modern African Studies, 37(1), 53-82.

Mignolo, W. (2003). Historias locales/diseños globales: colonialidad, conocimientos subalternos y pensamiento fronterizo (Trads. J. Madariaga y C. Vega Solís). Madrid: Akal.

Mignolo, W. (2004). Capitalismo y geopolítica del conocimiento. En S. Dube, I. Banerjee-Dube y W. Mignolo (Coords.), Modernidades coloniales: otros pasados, historias presentes (pp. 227-258). México: El Colegio de México.

Mignolo, W. (2010). Desobediencia epistémica (II), pensamiento independiente y libertad de-colonial (Trad. I. J. Herrera). Otros Logos, 1(1), 8-42.

Misser, F. (2019). Au Congo, le candidat butuu... est élu. Le Monde diplomatique. Recuperado de https://www.monde-diplomatique. $\mathrm{fr} / 2019 / 03 / \mathrm{MISSER} / 59601$

MkandawiRe, T. (2001). Thinking about developmental states in Africa. Cambridge Journal of Economics, 25(3), 289-313.

Mkandawire, T. (2007). "Good governance": The itinerary of an idea. Development in Practice, 17(4/5), 679-681. https://doi. org/10.1080/09614520701469997

Monenembo, T. (2016). The return of presidents for life. Le Monde diplomatique. Recuperado de https://mondediplo. com/2016/01/11africa

Patrice Lumumba. The truth about a monstrous crime of the colonialists (1961). Moscú: Foreign Languages Publishing House.

Polet, F. (2016). République démocratique du Congo : la rue au centre du jeu politique. Alternatives Sud, 23(4): État des Resistances dans le Sud. Afrique, 133-140. París: Éditions Syllepse.

Raeymaekers, T. (2008). ¿Colapso u orden? Cuestionando el colapso del Estado en África. Relaciones Internacionales, (8), 33-55. Recuperado de https://revistas.uam.es/index.php/relacionesinternacionales/article/view/4910

Reno, W. (1997). Sovereignty and personal rule in Zaire. African Studies Quarterly, 1(3), 39-64.

RENO, W. (2006). Congo: From state collapse to 'absolutism', to state failure. Third World Quarterly, 27(1), 43-56.

RidaO, J. M. (1997). Kabila, señor de las incógnitas. Política Exterior, 11(58), 31-34, 37-51. 
Robinson, P. T. (1994). The National Conference phenomenon in francophone Africa. Comparative Studies in Society and History, 36(3), 575-610.

SAntos, B. de S. (2002). Para uma sociologia das Ausências e uma sociologia das emergências. Revista Crítica de Ciências Sociais, 63, 237-280. https://doi.org/10.4000/rccs.1285

SANTOS, B. de S. (2014). Justicia entre saberes. Epistemologías del Sur contra el epistemicidio. Madrid: Morata.

Schoenholtz, A. (1987). The I.M.F. in Africa: Unnecessary and undesirable western restraints on development. The Journal of Modern African Studies, 25(3), 403-433.

Special National Intelligence Estimate (1961). Main elements in the Congo situation. Foreign Relations of the United States 19611963, 20: Congo Crisis, 65-61. Washington, D.C. Recuperado de https://history.state.gov/historicaldocuments/frus1961-63v20/ d2

Svampa, M. (2016). El concepto de crisis en Reinhart Koselleck. Polisemias de una categoría histórica. Anacronismo e Irrupción, 6(11), 131-151.

Wallerstein, I. (1993). The geoculture of development, or the transformation of our geoculture. Asian Perspective, 17(2), 211225.

Wallerstein, I. (1994). El derrumbe del liberalismo. Secuencia, (28), 137-154. https://doi.org/10.18234/secuencia.v0i28.455

Wallerstein, I. (1996). Después del liberalismo. México: Siglo XXI.

Willame, J.-C. (1971). Politics and power in Congo-Kinshasa. Africa Report, 16(1), 14-17.

World BANK (2004). Transitional support strategy for the Democratic Republic of the Congo (Reporte núm. 27751). Washington, DC: World Bank.

Young, C. y Turner, T. (1985). The rise and decline of the Zairian state. Madisson, WI: The University of Wisconsin Press.

ZARTMAN, W. (1995). Collapsed states: The disintegration and restoration of legitimate authority. Boulder, CO: Lynne Rienner.

ZiBECHI, R. (3 de junio de 2011). Las revoluciones de la gente común. La Jornada. Recuperado de https://www.jornada.com. $\mathrm{mx} / 2011 / 06 / 03 /$ opinion/023a1pol 
Marco Antonio Reyes Lugardo es profesor-investigador de tiempo completo adscrito a la Academia de Historia y Sociedad Contemporánea de la Universidad Autónoma de la Ciudad de México, plantel Cuautepec. Es doctor en estudios de Asia y África por El Colegio de México y candidato a miembro del Sistema Nacional de Investigadores del Consejo Nacional de Ciencia y Tecnología, México.

http://orcid.org/0000-0003-0525-4969 ryslugardo@hotmail.com 
